\title{
Comparison of immune responses of Schistosoma mansoni-infected mice with distinct chronic forms of the disease
}

\author{
Luciana M. Silva ${ }^{\text {a }}$, Sheilla A. Oliveira ${ }^{\text {a,c }}$, Ricardo Ribeiro-dos-Santos ${ }^{b}$, \\ Zilton A. Andrade ${ }^{a}$, Milena B.P. Soares ${ }^{b, *}$ \\ ${ }^{a}$ Laboratory of Experimental Pathology, Gonçalo Moniz Research Center, Oswaldo Cruz Foundation, Rua Waldemar Falcão, 121 Brotas, \\ Salvador, BA 40295-001, Brazil \\ ${ }^{\mathrm{b}}$ Laboratory of Tissue Bioengineering and Immunopharmacology, Gonçalo Moniz Research Center, Oswaldo Cruz, Foundation, Rua \\ Waldemar Falcão, 121 Brotas, Salvador, BA 40295-001, Brazil \\ ${ }^{c}$ Aggeu Magalhães Research Center, Oswaldo Cruz Foundation, Av. Moraes Rego, s/n-Cidade Universitária, Recife, PE 50670-420, Brazil
}

Received 27 November 2003; received in revised form 27 April 2004; accepted 10 May 2004

\begin{abstract}
Background: Schistosoma mansoni-infected mice tend to present with either one of two different hepatic pathological patterns during chronic infection: periportal fibrosis (PF) with portal concentration of periovular granulomas and fibrosis or isolated granulomas (IG), with scattered periovular granulomas within the liver. These are models for the two clinical presentations of schistosomiasis, the severe hepatosplenic and the mild intestinal forms. In the present work, we examined the relationship between the development of these histopathological aspects and immunological markers in S. mansoni-infected mice. Although $\mathrm{BALB} / \mathrm{c}$ mice with PF and IG had similar egg numbers in the liver, PF mice had higher liver collagen contents than mice with IG. Cultured spleen cells from mice with PF and IG had similar proliferation 20 and 40 weeks after S. mansoni infection upon stimulation with parasite egg antigen (SEA) or mitogen (Con A). Production of IL-4 upon SEA stimulation was higher in cell cultures from mice with PF, whereas IL-5 and IFN- $\gamma$ levels were not statistically different between PF and IG groups. Mice with IG had similar serum concentrations of total IgE and anti-SEA IgG1, IgG2a, IgG2b and IgG3 compared to sera from PF mice. Levels of IgG1 and IgG2a antibodies were the highest and the lowest detected, respectively. In conclusion, isogenic BALB/c mice infected with S. mansoni that develop periportal fibrosis or isolated granulomas have similar immunological patterns despite the two pathologic forms of schistosomal liver fibrosis.
\end{abstract}

(C) 2004 Elsevier B.V. All rights reserved.

Keywords: Schistosoma mansoni; Immune response; Liver fibrosis; Isogenic mice

\footnotetext{
* Corresponding author. Tel.: +55 71356 8787x260; fax: +55 71356 8784x292.
}

E-mail address: milena@cpqgm.fiocruz.br (M.B.P. Soares). 


\section{Introduction}

Schistosoma mansoni-induced morbidity and mortality are of major concern in tropical regions of the world. In most individuals, the infection is relatively benign. Patients with the asymptomatic or intestinal form of the disease may only experience occasional gastrointestinal discomfort. However, $10 \%$ of infected people in endemic areas may develop the severe, hepatosplenic form of disease, characterized by the presence of periportal fibrosis (PF) (Symmer's clay pipestem fibrosis), splenomegaly, portal hypertension, collateral circulation, esophageal varices, and hematemesis (Nash et al., 1982; Andrade and Bina, 1983; Andrade and Van Marck, 1984; Chen and Mott, 1988).

The factors that cause the development of periportal fibrosis associated with hepatosplenic disease are poorly understood. Although high worm load is considered the major factor involved in pathogenesis (Cheever, 1968a; Coura and Conceição, 1981), additional factors, such as host genetics and immunologic response profiles, may play a role, since not all heavily-infected people will develop hepatosplenic disease. Some previous studies have demonstrated an association between Th2 cytokine production and intensity of infection (Zwingerber et al., 1991; Williams et al., 1994; Araújo et al., 1994; Viana et al., 1994). These studies have found that the intensity of $S$. mansoni infection in schistosomiasis patients was positively correlated with IL-4 levels and negatively correlated with IFN- $\gamma$ production. However, in another study, the development of hepatosplenic disease was associated with Th1 cytokine responses (Mwatha et al., 1998).

In the murine model, the pathogenesis of pipestem fibrosis resembles that in humans (Warren, 1966; Andrade, 1987). Periportal fibrosis appears only in a certain percentage of chronically infected mice, even when inbred animals are used, indicating that factors other than worm burden, time and genetic background are involved (Andrade and Cheever, 1993). The role of immune responses in granuloma formation has been well studied in $S$. mansoni-infected mice. However, little is known about the immune responses in mice with pipestem fibrosis. Various studies have demonstrated the importance of fibrosis regulation by cytokines (Henri et al., 2002; Vaillant et al., 2001; Cheever et al., 1998). In a study using $S$. mansoni-infected CBA/J mice, it was demonstrated an association between the production of anti-idiotype antibodies and pathology (Montesano et al., 1997). In the present work, we compared the immune response of inbred mice with periportal fibrosis or with isolated scattered granulomas following $S$. mansoni infection.

\section{Materials and methods}

\subsection{Mice}

Male, 4-week-old BALB/c mice were used for infection with $S$. mansoni. Swiss Webster mice were used to obtain schistosome eggs for antigen preparations. All mice were raised and maintained at the animal facilities of Gonçalo Moniz Research Center, and provided with rodent diet and water ad libitum. All mice were sacrificed and treated in accordance with the Oswaldo Cruz Foundation Commission for Experiments in Laboratory Animals.

\subsection{S. mansoni infection}

$\mathrm{BALB} / \mathrm{c}$ mice were infected transcutaneously with 30 S. mansoni cercariae of the Feira de Santana strain (Andrade and Sadigursky, 1985). This strain has been maintained through successive passages in laboratory-raised Biomphalaria glabrata. Sixteen weeks after infection, a liver biopsy was performed in order to identify the mice developing periportal fibrosis or isolated scattered granulomas. Groups of mice were bled for serum collection and sacrificed 20 or 40 weeks after infection. To evaluate the degree of infection, a liver fragment from each mouse was digested in $0.5 \% \mathrm{NaOH}$ for egg counting, according to the methodology described by Cheever (1968b).

\subsection{SEA preparation}

To obtain S. mansoni eggs, Swiss Webster mice were infected with 100 S. mansoni cercariae of the Feira de Santana strain. Mice were sacrificed 7-8 weeks after infection, and livers were homogenized in $1.7 \%$ saline solution. Homogenate was then filtered 
and centrifuged at $1300 \mathrm{rpm}$ at $4{ }^{\circ} \mathrm{C}$. After purification in a percoll gradient, eggs were homogenized using a Potter homogenizer and submitted to four cycles of freezing and thawing. The suspension was then centrifuged at $14,000 \mathrm{rpm}$ at $4{ }^{\circ} \mathrm{C}$. The aqueous fraction was then collected, sterilized in a gamma-ray irradiator and the protein concentration determined by a fluorescence protein assay (Stein et al., 1973).

\subsection{Histopathological analyses and collagen determination}

Liver fragments were fixed in Bouin's fluid. The material was embedded in paraffin and the sections stained with hematoxylin and eosin, and with the picrosirius-red method for collagen (Junqueira et al., 1979). Histological sections stained with picrosirius-red were analyzed by automatic morphometry using a color digital video camera attached to an Olympus AX-70 microscope. The images were analyzed using the Image Pro Program (Media Cybernetics, Carlsbad, CA). The percentage of fibrosis was evaluated in a total section area of $12 \mathrm{~mm}^{2}$ per animal.

For determination of collagen concentration, a liver fragment of approximately $200 \mathrm{mg}$ was fixed in neutral buffered formalin, and the concentration of hydroxyproline was measured using the technique described by Bergman and Loxley (1963). Briefly, the liver fragment was digested in $6 \mathrm{~N} \mathrm{HCl}$ for $18 \mathrm{~h}$ at $110^{\circ} \mathrm{C}$. After neutralization with $\mathrm{NaOH}$, levels of hydroxyproline were determined in a colorimetric assay using Ehrlich's reagent. Preparations were read in a spectrophotometer at $558 \mathrm{~nm}$.

\subsection{Antibody detection}

The levels of SEA-specific IgG1, IgG2a, IgG2b and IgG3 antibodies were determined by ELISA. Microtiter plates (Nunc Maxi Sorp) were sensitized overnight at $4{ }^{\circ} \mathrm{C}$ with SEA at a concentration of $3 \mu \mathrm{g} / \mathrm{well}$ in $0.1 \mathrm{M} \mathrm{NaHCO}_{3}$ (pH 9.6). After a blocking step with $5 \%$ fetal bovine serum in PBS, plates were incubated for $2 \mathrm{~h}$ at room temperature with sera from infected mice. Plates were incubated with biotin anti-mouse IgG1, IgG2a, IgG2b, or IgG3 (PharMingen), followed by addition of streptavidin-peroxidase conjugate (Sigma). Total serum IgE was determined by a sandwich ELISA using purified anti-IgE an- tibody for capture and biotinylated anti-IgE antibody for detection (PharMingem), followed by streptavidin-peroxidase conjugate (Sigma). Reaction was developed using 3,3',5,5'-tetramethylbenzidine (TMB) peroxidase substrate solution (Kirkegaard and Perry). Plates were read at $450 \mathrm{~nm}$ in a microplate reader (Molecular Devices, Sunnyvale, CA).

\subsection{Spleen cell culture}

Spleen cell suspensions were prepared in RPMI medium (Life Technologies, GIBCO-BRL, Gaithersburg, MD) supplemented with 10\% FCS (Hyclone, Logan, UT), L-glutamine (2 $\mathrm{mM})$, vitamins, sodium pyruvate $(1 \mathrm{mM})$, HEPES $(10 \mathrm{mM}), 5 \times 10^{-5} \mathrm{M}$ of 2-mercaptoethanol, and gentamycin $(50 \mu \mathrm{g} / \mathrm{ml})$ (Sigma). For cytokine determination, spleen cells were cultured in 24 well plates and stimulated with $10 \mu \mathrm{g} / \mathrm{ml} \mathrm{SEA}$. Cell-free supernatants were collected after $48 \mathrm{~h}$ and stored at $-20^{\circ} \mathrm{C}$ for cytokine analysis. To evaluate the proliferative response, splenocytes were plated in 96 -well plates at $4 \times 10^{5} /$ well in $200 \mu \mathrm{l}$ and triplicate wells were stimulated with concanavalin A (Con A; Sigma) or SEA for $72 \mathrm{~h}$, as described in figure legends. After pulsing with $1 \mu \mathrm{Ci}$ of [methyl- $\left.{ }^{3} \mathrm{H}\right]$-thymidine (Amersham, Little Chalfont, UK) for $14-18 \mathrm{~h}$, proliferation was assessed by measurement of ${ }^{3} \mathrm{H}$-thymidine uptake in a $\beta$-plate counter (Packard, Meriden, CT).

\subsection{Measurement of cytokine production}

Supernatants of splenocyte cultures were tested for IFN- $\gamma$, IL-4, and IL-5 contents by ELISA, using antibody pairs from PharMingen, following manufacturer's instructions. Reaction was developed using the $3,3^{\prime}, 5,5^{\prime}$-tetramethylbenzidine (TMB) peroxidase substrate (Kinkergaard \& Perry Laboratories, Gaithersburg, MD) and read at $450 \mathrm{~nm}$.

\subsection{Statistical analyses}

Data were analyzed using Student's $t$-test, for normally-distributed data, or the Mann Whitney test, for non-normally distributed data, as indicated in the text. Differences were considered significant when $P$ $<0.05$. 


\section{Results}

\subsection{Development of pipestem fibrosis in $S$. mansoni-infected BALB/c mice}

BALB/c mice infected with $S$. mansoni were submitted to liver biopsy 16 weeks after infection, in order to identify the histopathological pattern of each individual. The histopathological diagnosis, made blindly by two independent observers, demonstrated that $37(59 \%)$ had periportal fibrosis, $10(16 \%)$ mice had scattered granulomas, and 16 (25\%) presented a mixed picture with scattered granulomas and mild fibrosis in portal space. All mice with mixed histopathological presentation were excluded from this study.

Parasite burden was evaluated by the number of schistosome eggs found per gram of liver at 20 and 40 weeks after infection. No significant differences were observed between the number of eggs in mice with pipestem fibrosis and with scattered granulomas, at either 20 or 40 weeks following infection (Fig. 1).

\subsection{Quantification of liver collagen in $S$.} mansoni-infected mice with different histopathologic patterns

Collagen in liver tissue was quantified using two different methods. First, the amount of collagen was estimated by measuring the hydroxyproline content in liver fragments from S. mansoni-infected mice. Although the levels of hydroxyproline in liver fragments of mice with periportal fibrosis were higher than those of mice with scattered granulomas, the differences were not statistically significant (Fig. 2A and B). Second, picrosirius red-stained sections were morphometrically analyzed for collagen quantification. Twenty weeks after infection, the areas staining positively for collagen were significantly larger in liver sections from mice with periportal fibrosis than in those from mice with scattered granulomas (Fig. 2C).

\subsection{Comparison of proliferative and cytokine responses}

The proliferation indices of spleen cells from mice with scattered granulomas upon stimulation with Con A or SEA were slightly higher compared to those of mice with periportal fibrosis (Fig. 3A). However, the differences were not statistically significant, in the two time points analyzed. The response to SEA stimulation at 40 weeks after infection was decreased in both groups compared to the response observed at 20 weeks after infection (Fig. 3B).

Twenty weeks after infection, the production of IFN- $\gamma$ by spleen cells stimulated with SEA was similar in both groups of mice (Fig. 4A; $P>0.05$ ). The levels of IL-4 in cultures of spleen cells from mice with periportal fibrosis were higher than those of mice with scattered granulomas upon stimulation with SEA 20 weeks after infection (Fig. 4B). The levels of IL-5 were similar upon stimulation with SEA at 20 weeks after infection (Fig. 4C). Forty weeks after infection, cytokine levels were undetectable in splenocyte cultures stimulated with SEA in both groups of mice (not shown).
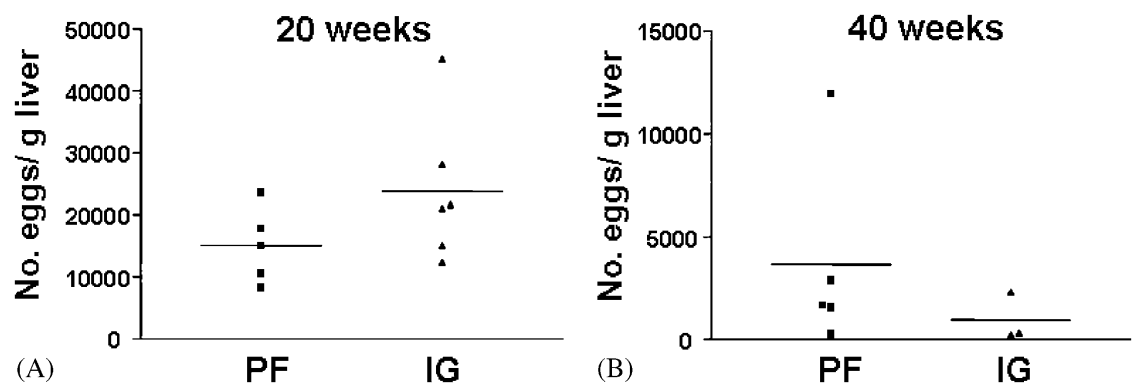

Fig. 1. Parasite load in S. mansoni-infected mice. BALB/c mice were infected with 30 cercariae of S. mansoni and sacrificed 20 (A) or 40 (B) weeks after infection. The number of eggs was determined by counting after digestion of liver fragments. Data represent egg numbers per liver gram of individual mice. PF: periportal fibrosis; IG: isolated granulomas. 
20 weeks

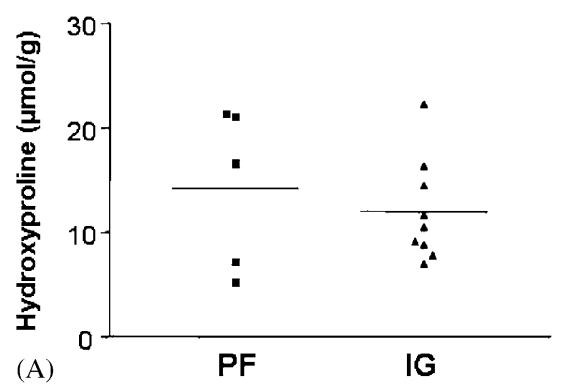

40 weeks

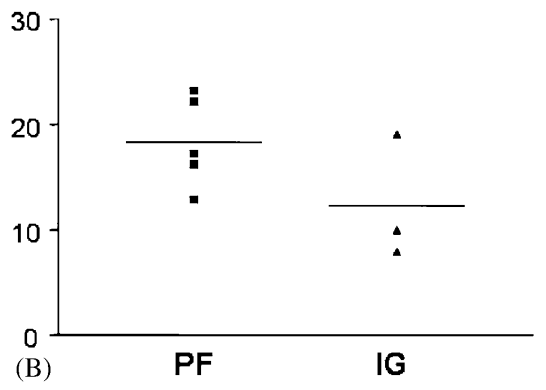

(C)

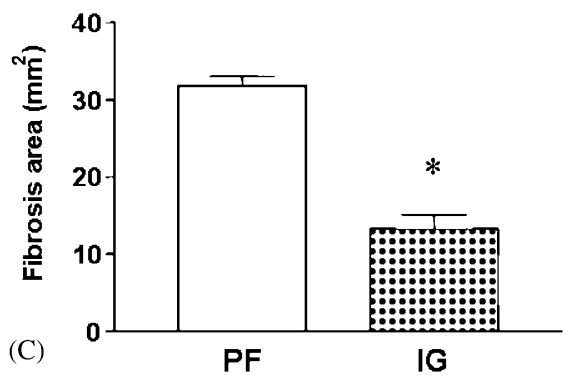

Fig. 2. Quantification of liver collagen. Liver fragments of BALB/c mice were obtained 20 (A and C) or 40 (B) weeks after infection. (A and B) The hydroxyproline levels per $\mathrm{g}$ of liver of individual mice were determined by colorimetric assay, as described in Material and Methods. (C) Morphometrical evaluation of fibrotic areas of liver sections stained with picrosirius red. Bars represent the means \pm S.E.M. of four individual mice. PF: periportal fibrosis; IG: isolated granulomas. $P<0.002$.

\subsection{Antibody production in S. mansoni-infected mice}

The levels of SEA-specific antibodies were determined 20 and 40 weeks after infection. IgG1 was the predominant isotype in both time point analyzed. No significant differences were observed in the levels of IgG1, IgG2a, IgG2b and IgG3 SEA-specific antibodies when animals with scattered granulomas and periportal fibrosis were compared (Fig. 5). Additionally, the levels of total serum IgE were similar in both groups of mice (Fig. 5).

\section{0 weeks}
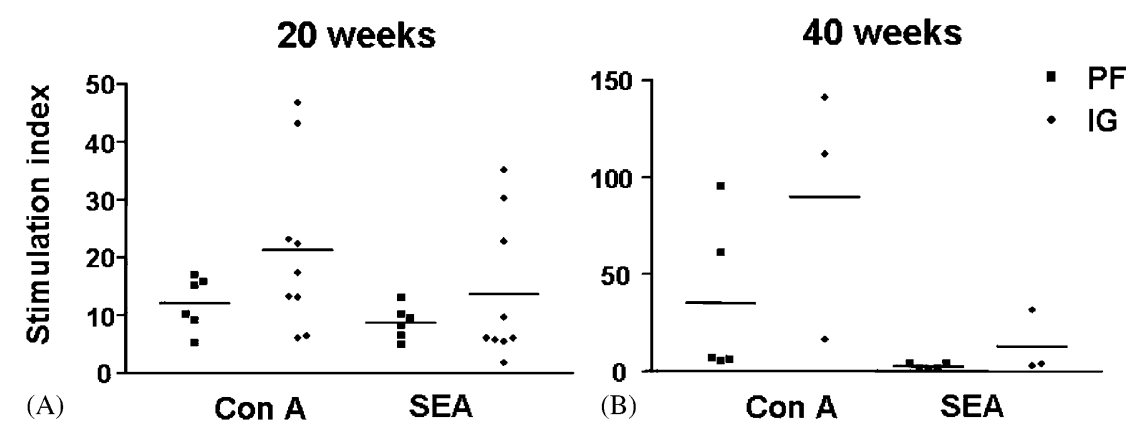

Fig. 3. Proliferative responses of spleen cells from $S$. mansoni-infected mice. Spleen cells of BALB/c mice with pipestem fibrosis or with scattered granulomas were obtained 20 (A) or 40 (B) weeks after infection and stimulated with Con A (1 $\mu \mathrm{g} / \mathrm{ml})$ or SEA (5 $\mu \mathrm{g} / \mathrm{ml})$. Proliferative responses were determined $72 \mathrm{~h}$ later by ${ }^{3} \mathrm{H}$-thymidine uptake. Data represent the stimulation index compared to untreated control cultures of individual mice. PF: periportal fibrosis; IG: isolated granulomas. 

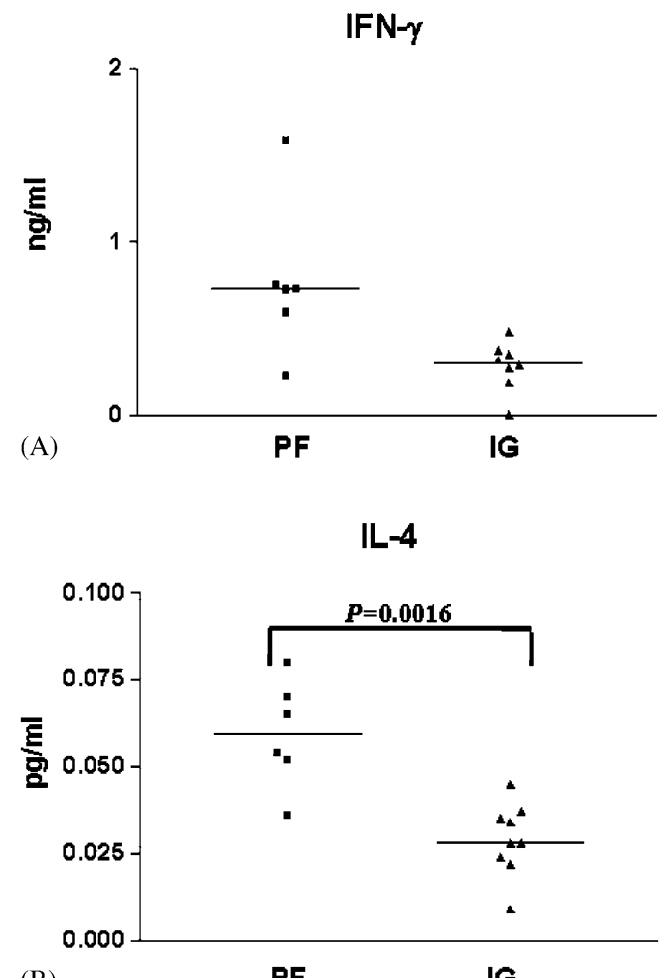

(B)

\section{IL-5}

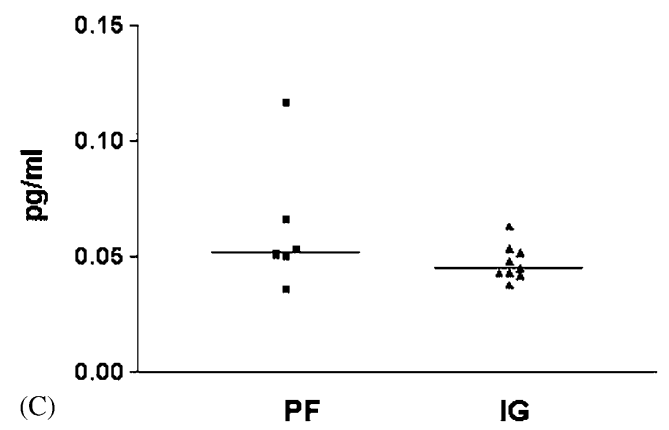

Fig. 4. Cytokine production of spleen cells 20 weeks after $S$. mansoni infection. Spleen cells from BALB/c mice with periportal fibrosis or with isolated granulomas were obtained 20 weeks after infection and cultured in 24-well plates in the presence of SEA $(5 \mu \mathrm{g} / \mathrm{ml})$. Cell-free supernatants were collected $48 \mathrm{~h}$ later and levels of IFN- $\gamma$ (A), IL-4 (B) and IL-5 (C) were determined by ELISA. Data represent values of individual mice.

\section{Discussion}

To analyze the factors involved in the development of severe hepatosplenic schistosomiasis in humans
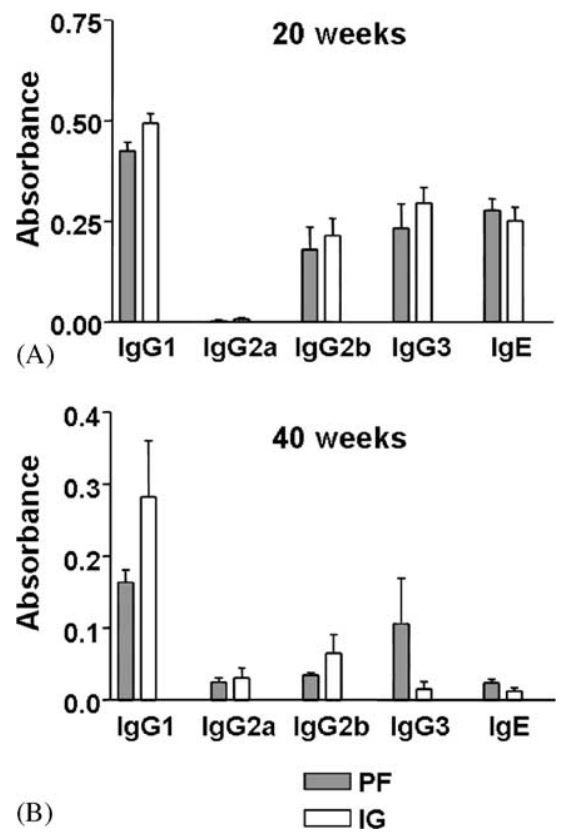

Fig. 5. Analysis of antibody production in S. mansoni-infected mice. Serum levels of SEA-specific IgG1, IgG2a, IgG2b, IgG3 antibodies and total IgE antibodies were measured 20 (A) or 40 (B) weeks of infection by ELISA. Data represent the mean \pm S.D. of six to nine (A) and three to six (B) mice per group.

seems a difficult task because of the numerous variables present. Genetic background, variations in size and number of exposures to infection, and immune responses to several stimuli are some of the potential risk factors. In this study we compared the immune response of $S$. mansoni-infected mice at the two histopathological poles: the severe periportal fibrosis and the benign isolated granulomas. In our model, syngeneic mice were infected in the same conditions (number of cercariae and time of exposure), allowing us to investigate the association between immune responses and histopathological findings in isolation.

A high percentage $(59 \%)$ of BALB/c mice developed periportal fibrosis upon $S$. mansoni infection. Studies using other mouse strains, such as outbred Swiss Webster (Santos et al., 2000) or inbred CBA/J (Henderson et al., 1993), reported a smaller percentage of mice developing periportal fibrosis after $S$. mansoni infection (11 and 20\%, respectively). The finding that a higher percentage of BALB/c mice develop periportal fibrosis suggests that host genetic factors may in- 
deed play a role, either in being more permissive to the worms or in the predisposition for the development of more marked tissue reactions.

One of the factors known to affect the collagen deposition and development of periportal fibrosis is the parasite load. Heavy $S$. mansoni-infections were associated with severe hepatosplenic form in S. mansoni-infected individuals (Cheever, 1969). Although the mice used in our experiments were exposed to the same number of parasites, it was possible for the parasite load to differ slightly between animals, which may have influenced the development of the histopathological patterns. However, no significant differences in the number of eggs in livers of mice with scattered granulomas and with periportal fibrosis were observed at the time points studied. This indicates that the number of eggs is not the only factor to determine the progression to periportal fibrosis.

In this study, an association was observed between levels of collagen by measurement of hydroxyproline content in liver tissue and severity of disease. This association was supported by morphometrical analysis. In this case, the morphometry was more sensitive to detect the differences than the hydroxyproline method. Cheever (1997) has demonstrated that the association between egg numbers and fibrosis is not linear in mice. Although heavy infections induced higher percentage of hepatic fibrosis, the percentage of fibrosis per egg numbers was lower (Cheever, 1968a). These findings are in agreement with the lack of correlation between egg numbers and fibrosis observed in our study.

Cytokines are important regulators of immunoinflammatory responses and play a major role in the regulation of fibrosis deposition and degradation (Vaillant et al., 2001). Several reports in the literature demonstrated alterations in $\mathrm{T}$ helper cytokine profiles during the formation of granulomatous reaction (Pearce et al., 1991; Grzych et al., 1991; Fallon et al., 1998). Egg deposition is a stimulus to Th2-associated cytokine production, and thus the immune responses of mice during the chronic infection are associated with this profile (Grzych et al., 1991). In our study, proliferative responses and production of IFN- $\gamma$ was highly suppressed, especially after 40 weeks of infection. Although spleen cells of mice with pipestem fibrosis produced higher levels of Th2 cytokines (IL-4) than spleen cells from mice with isolated granulomas, the predominant cytokines in PF and IG groups were
IL-4 and IL-5, indicating a Th2 profile along with high IgG1 and IgE levels. Thus, the development of pipestem fibrosis did not correlate with significant alterations in immunological profile at a systemic level. Although we did not observe significant differences in the immune responses of GI and PF mice at 20 or 40 weeks of infection, we cannot rule out by the present study that they occur early in the infection (prior to the establishment of the histopathological pattern).

It is possible that differences in the localization egg deposition affect the hepatic microvasculature of $S$. mansoni-infected mice, with may influence progression to periportal fibrosis. In a study of the microvasculature of mice with PF and IG we observed alterations in the periportal microvasculature of mice with periportal fibrosis that were absent in mice with isolated granulomas (Silva et al., 2003; Grzych et al., 1991). This apparently random fibrosis-promoting pattern of egg deposition may locally affect the production of fibrosis-inducing cytokines such as TGF- $\beta$ and TNF- $\alpha$, a possibility that we are currently investigating.

\section{Acknowledgements}

This work was supported by Conselho Nacional de Desenvolvimento Científico e Tecnológico (CNPq), PRONEX (MCT) and Fundação Oswaldo Cruz (FIOCRUZ). The authors wish to thank Rejane M. C. Menezes, Antônio Carlos S. Santos and Moema C. Bellintani for technical support and Dr. Brendan L. Flannery for review of the manuscript.

\section{References}

Andrade, Z.A., Bina, J.C., 1983. The pathology of the hepatosplenic form of schistosomiasis mansoni in its advanced form (study of 232 complete necropsies). Mem. Inst. Oswaldo Cruz 78, 285-305.

Andrade, Z.A., Cheever, A.W., 1993. Characterization of the murine model of schistosomal hepatic periportal fibrosis ("pipestem" fibrosis). Int. J. Exp. Pathol. 74, 195-202.

Andrade, Z.A., Sadigursky, M., 1985. Um estudo comparativo das cepas Feira de Santana (Bahia) e Porto Rico do Schistosoma mansoni na infecção experimental do camundongo. Mem. Inst. Oswaldo Cruz 80, 37-40.

Andrade, Z.A., Van Marck, E.A.E., 1984. Schistosomal glomerular disease. Mem. Inst. Oswaldo Cruz 79, 499-506. 
Andrade, Z.A., 1987. Pathogenesis of pipestem fibrosis of the liver (experimental observation on murine schistosomiasis). Mem. Inst. Oswaldo Cruz 82, 325-334.

Araújo, M.I., Bacellar, O., Ribeiro-de-Jesus, A., Carvalho, E.M., 1994. The absence of gamma-interferon production to $S$. mansoni antigens in patients with schistosomiasis. Braz. J. Med. Biol. Res. 27, 1619-1625.

Bergman, I., Loxley, R., 1963. Two improved and simplified methods for the spectrometric determination of hydroxyproline. Anal. Chem. 35, 1961-1965.

Cheever, A.W., Jankovic, D., Yap, G.S., Kullberg, M.C., Sher, A., Wynn, T.A., 1998. Role of cytokines in the formation and downregulation of hepatic circumoval granulomas and hepatic fibrosis in Schistosoma mansoni-infected mice. Mem. Inst. Oswaldo Cruz 93, 25-32.

Cheever, A.W., 1968a. A quantitative post-mortem study of schistosomiasis mansoni in man. Am. J. Trop. Med. Hyg. 17, 38-64.

Cheever, A.W., 1968b. Conditions affecting the accuracy of potassium hydroxide digestion technique for counting Schistosoma mansoni eggs in tissues. Bull. WHO 39, 328-331.

Cheever, A.W., 1969. Quantitative comparison of the intensity of Schistosoma mansoni infections in man and experimental animals. Trans. R. Soc. Trop. Med. Hyg. 63, 781-795.

Cheever, A.W., 1997. Differential regulation of granuloma size and hepatic fibrosis in schistosoma infections. Mem. Inst. Oswaldo Cruz 92, 689-692.

Chen, M.G., Mott, K.E., 1988. Progress in assessment of morbidity due to Schistosoma mansoni infection. A review of recent literature. Trop. Dis. Bull. 85, 1-56.

Coura, J.R., Conceição, M.J., 1981. Correlação entre carga parasitária de $S$. mansoni e gravidade das formas clínicas em uma comunidade rural de Minas Gerais. Rev. Soc. Bras. Med. Trop. 14, 93-97.

Fallon, P.G., Smith, P., Dunne, D.W., 1998. Type 1 and type 2 cytokine-producing mouse $\mathrm{CD}^{+}{ }^{+}$and $\mathrm{CD} 8^{+} \mathrm{T}$ cells in acute Schistosoma mansoni infection. Eur. J. Immunol. 28, 1408S1416S.

Grzych, J.M., Pearce, E., Cheever, A.W., Caulada, Z.A., Caspar, P., Heiny, S., Lewis, F., Sher, A., 1991. Egg deposition is the major stimulus for the production of Th2 cytokines in murine schistosomiasis mansoni. J. Immunol. 146, 13221327.

Henderson, G.S., Nix, N.A., Montesano, M.A., Gold, D., Freeman Jr., G.L., McCurley, T.L., Colley, D.G., 1993. Two distinct pathological syndromes in male $\mathrm{CBA} / \mathrm{J}$ inbred mice with chronic Schistosoma mansoni infections. Am. J. Pathol. 142, 703-714

Henri, S., Chevillard, C., Mergani, A., Paris, P., Gaudart, J., Camilla, C., Dessein, H., Montero, F., Elwali, N.E., Saeed, O.K., Magzoub, M., Dessein, A.J., 2002. Cytokine regulation of periportal fibrosis in humans infected with Schistosoma mansoni: IFN-gamma is associated with protection against fibrosis and TNF-alpha with aggravation of disease. J. Immunol. 169, 929-936.
Junqueira, L.C.U., Bignolas, G., Brentani, R., 1979. Picrosirius staining plus polarization microscopy, a specific method for collagen detection in tissue sections. Histochem. J. 11, 447455 .

Montesano, M.A., Freeman Jr., G.L., Secor, W.E., Colley, D., 1997. Immunoregulatory idiotypes stimulate $\mathrm{T}$ helper 1 cytokine responses in experimental Schistosoma mansoni infections. J. Immunol. 158, 3800-3804.

Mwatha, J.K., Kimani, G., Kamau, T., Mbugua, G.G., Ouma, J.H., Mumo, J., Fulford, A.J., Jones, F.M., Butterworth, A.E., Roberts, M.B., Dunne, D.W., 1998. High levels of TNF, soluble TNF receptors, soluble ICAM-1, and IFN-gamma, but low levels of IL-5, are associated with hepatosplenic disease in human schistosomiasis mansoni. J. Immunol. 160, 1992-1999.

Nash, T.E., Cheever, A.W., Ottesen, E.A., Cook, J.A., 1982. Schistosome infections in humans: perspectives and recent findings. NIH conference. Ann. Intern. Med. 97, 740-754.

Pearce, E.J., Caspar, P., Grzych, J.M., Lewis, F.A., Sher, A., 1991. Downregulation of Th1 cytokine production accompanies induction of Th2 responses by a parasitic helminth, Schistosoma mansoni. J. Exp. Med. 173, 159-166.

Santos, B.A., Souza, M.M., Andrade, A., 2000. Reinfecções e desenvolvimento da fibrose periportal esquistossomótica no modelo murino. Rev. Soc. Bras. Med. Trop. 33, 197-200.

Silva, L.M., Ribeiro-dos-Santos, R., Soares, M.B.P., Andrade, Z.A., 2003. The Mouse Model of Schistosomal Periportal (Pipestem) Fibrosis. Pathol. Features, submitted for publication.

Stein, S., Bohlen, P., Stone, J., Dairman, W., 1973. Udenfriend S. Amino acid analysis with fluorescamine at the picomole level. Arch. Biochem. Biophys. 155, 202-212.

Vaillant, B., Chiaramonte, M.G., Cheever, A.W., Soloway, P.D., Wynn, T.A., 2001. Regulation of hepatic fibrosis and extracellular matrix genes by the response: new insight into the role of tissue inhibitors of matrix metalloproteinases. J. Immunol. 167, 7017-7026.

Viana, I.R., Sher, A., Carvalho, O.S., Massara, C.L., EloiSantos, S.M., Pearce, E.J., Colley, D.G., Gazzinelli, G., Correa-Oliveira, R., 1994. Interferon-gamma production by peripheral blood mononuclear cells from residents of an area endemic for Schistosoma mansoni. Trans. R. Soc. Trop. Med. Hyg. 88, 466-470.

Warren, K.S., 1966. The pathogenesis of 'clay-pipe stem cirrhosis' in mice with chronic schistosomiasis mansoni, with a note on the longevity of the schistosomes. Am. J. Pathol. 49, 477-489.

Williams, M.E., Montenegro, S., Domingues, A.L., Wynn, T.A., Teixeira, K., Mahanty, S., Coutinho, A., Sher, A., 1994. Leukocytes of patients with Schistosoma mansoni respond with a Th2 pattern of cytokine production to mitogen or egg antigens but with a Th0 pattern to worm antigens. J. Infect. Dis. 170, 946-954.

Zwingerber, K., Hohmann, A., Cardoso de Brito, M., Ritter, M., 1991. Impaired balance of interleukin-4 and interferon(production in infections with Schistosoma mansoni and intestinal nematodes. Scand. J. Immunol. 34, 243-251. 